\title{
Are Digital Models Replacing Plaster Casts?
}

\section{Sercan Akyalcin*}

Sercan Akyalcin, DDS, PhD, Assistant Professor, University of Texas Science Health Science Center at Houston, School of Dentistry, Department of Orthodontics, USA

Digital technology has vastly integrated into dental practice via recent advances in computer sciences. All the diagnostic information including patient history, photographs, radiographs, treatment plans and progress notes, as well as dental casts can now be stored electronically without the need for additional space in the office, thus reducing the costs involved. Aside from the advantage of accessing the data immediately, the ability to examine and analyze models digitally, and the facilitation of treatment planning presentations on today's high-definition computer screens is more appealing than plaster models. Furthermore, physical plaster models are also subject to degradation and breakage. But are we ready to completely replace plaster casts, which have been the standard of care in dentistry?

Digital models can only offer a valid alternative to plaster models if they are proven to be as accurate. University studies [1-7], which compared the conventional models to digital models, indicated that reliable measurements for tooth size, arch length, space analysis, overjet, overbite, and the Bolton ratio can be attained. As a result those studies concluded that digital models are clinically acceptable in initial diagnosis and treatment planning despite the occurrence of some statistically significant differences in the variables between the analog and the digital formats. When individual two-point linear measurements like inter-molar [2,8] and inter-canine-width $[2,8]$, tooth size [7], tooth height [8], overjet [1,2,5], and overbite [1,2,5] were compared between the conventional plaster and digital models, average mean differences varied between 0.03 to $0.4 \mathrm{~mm}$. All realworld measurements, as we know, are made with some degree of error. A small range up to $0.5 \mathrm{~mm}$ may include operator error and may, therefore, be considered as clinically acceptable. However, the picture gets a little blurrier for some of the other more complicated measurements. For instance, maxillary arch length [6], amount of mandibular space available [2], and irregularity index [5] values indicated mean differences of $1.47,1.69$, and $2.71 \mathrm{~mm}$, respectively between the classic and digital models. Needless to say if the average of absolute means are taken into account, much higher differences may be observed and clinical concerns may, therefore, be highlighted. Speculated cause of these results and variability between different studies can be handling techniques/operator errors [9], impression materials $[9,10]$, and the inevitable differences between the proprietary software used. Considering the differences in the generation of digital study models, one can understand that surface scanning, scanning through slices, or scanning directly from the impression material and the construction of the final digital model with proprietary algorithms may slightly alter the $3 \mathrm{D}$ volume and any spatial relation on it. More research is required to quantitatively examine and compare the $3 \mathrm{D}$ surface characteristics of the digital models because a $2 \mathrm{~mm}$ difference may actually affect the treatment plan. Nevertheless, a promising finding is that only $6 \%$ of proposed treatment plans are subjected to change when conventional models are replaced with today's digital models [11]. Perhaps, elimination of the conventional impression step and generating dental models from CBCT images [12-14] will yield better reproducible results as a next step in the reproduction of digital models. There is further research going on in this area and the results will be of great interest to the clinicians. However, there is one limitation with this technique: $\mathrm{CBCT}$ can only be utilized universally if the radiation dose is safe. Obtaining CBCT in each and every step of the treatment may, therefore, not be ethically justified.

In the light of the current evidence, there is no doubt that digital models will take over conventional plaster casts in the near future. However, we are still facing standardization issues related to the protocols in generating digital dental models. A 3D dental model should be able to be reproduced, viewed, measured and stored regardless of the technique-specific details in a highly consistent manner in the far corners of the world until a global acceptance is achieved. Practitioners are encouraged to use both the plaster and digital models until they are able to confirm repeatedly accurate results related to their practice needs and treatment planning procedures.

'Take time to deliberate; but when the time for action arrives, stop thinking and go in.' --Andrew Jackson

\section{References}

1. Santoro M, Galkin S, Teredesai M, Nicolay O, Cangialosi TJ (2003) A comparison between digital models and conventional plaster models. Am J Orthod Dentofacial Orthop 124: 101-105.

2. Quimby ML, Vig KW, Rashid RG, Firestone AR (2004) The accuracy and reliability of measurements made on computer-based digital models. Angle Orthod 74: 298-303.

3. Goonewardene RW, Goonewardene MS, Razza JM, Murray K (2008) Accuracy and validity of space analysis and irregularity index measurements using digital models. Aust Orthod J 24: 83-90.

4. Leifert MF, Leifert MM, Efstratiadis SS, Cangialosi TJ (2009) Comparison of space analysis evaluations with digital models and plaster dental casts. Am J Orthod Dentofacial Orthop 136: 16.e1-4.

5. Stevens DR, Flores-Mir C, Nebbe B, Raboud DW, Heo G, et al. (2006) Validity reliability, and reproducibility of plaster vs digital study models: comparison of peer assessment rating and Bolton analysis and their constituent measurements. Am J Orthod Dentofacial Orthop 129: 794-803.

6. Mullen SR, Martin CA, Ngan P, Gladwin M (2007) Accuracy of space analysis with emodels and plaster models. Am J Orthod Dentofacial Orthop 132: 346352.

7. Horton HM, Miller JR, Gaillard PR, Larson BE (2010) Technique comparison for efficient orthodontic tooth measurements using digital models. Angle Orthod 80: 254-261.

8. Keating AP, Knox J, Bibb R, Zhurov Al (2008) A comparison of plaster, digital and reconstructed study model accuracy. J Orthod 35: 191-201.

9. Fleming PS, Marinho V, Johal A (2011) Orthodontic measurements on digita study models compared with plaster models: a systematic review. Orthod Craniofac Res 14: 1-16.

*Corresponding author: Sercan Akyalcin, DDS, PhD, Assistant Professor, Schoo of Dentistry, Department of Orthodontics, University of Texas Science Health Science Center at Houston, USA, Tel: 713-500-4219; Fax: 713-500-4123; E-mail: Sercan.Akyalcin@uth.tmc.edu

Received August 19, 2011; Accepted October 15, 2011; Published October 20 2011

Citation: Akyalcin S (2011) Are Digital Models Replacing Plaster Casts?. Dentistry 1:e102. doi:10.4172/2161-1122.1000e102

Copyright: (c) Akyalcin S. This is an open-access article distributed under the terms of the Creative Commons Attribution License, which permits unrestricted use, distribution, and reproduction in any medium, provided the original author and source are credited. 
10. Torassian G, Kau CH, English JD, Powers J, Bussa HI, et al. (2010) Digital models vs plaster models using alginate and alginate substitute materials. Angle Orthod 80: 474-481.

11. Rheude B, Sadowsky PL, Ferriera A, Jacobson A (2005) An evaluation of the use of digital study models in orthodontic diagnosis and treatment planning Angle Orthod 75: 300-304.

12. Kau CH, Littlefield J, Rainy N, Nguyen JT, Creed B (2010) Evaluation of CBCT digital models and traditional models using the Little's Index. Angle Orthod 80:435-439
13. Tarazona B, Llamas JM, Cibrian R, Gandia JL, Paredes V (2011) A comparison between dental measurements taken from CBCT models and those taken from a Digital Method. Eur J Orthod. [Epub ahead of print]

14. Creed B, Kau CH, English J, Xia JJ, Lee RP (2011) A Comparison of the Accuracy of Linear Measurements Obtained from Cone Beam Computerized Tomography Images and Digital Models. Semin Orthod 17: 49-56. 